\title{
ANÁLISE DE PROCESSOS E INSUMOS NA FABRICAÇÃO DE COSMÉTICOS NATURAIS
}

\author{
ANALYSIS OF PROCESSES AND INPUTS IN THE MANUFACTURE OF \\ NATURAL COSMETICS
}

\author{
Fabrina Barbieri Peres ${ }^{1}$ \\ Larissa Caliani Uemura ${ }^{2}$ \\ Larissa Zanghettin ${ }^{3}$
}

\begin{abstract}
RESUMO: Devido ao aumento da exigência e da vaidade dos consumidores do mercado atual, não é de estranhar o constante crescimento da indústria cosmética brasileira e o desenvolvimento de novos produtos buscando satisfazer, cada vez mais, o desejo dos consumidores. Com o aumento da utilização de cosméticos naturais, surgiu um novo nicho de mercado de cosméticos, chamado de "cosméticos verdes", que são produzidos apenas por produtos naturais e orgânicos. Posteriormente, em consequência, surgiram os "consumidores verdes", adeptos ao consumo de cosméticos que não utilizam substâncias sintéticas e ou derivados animais, devido ao fato destes serem mais sustentáveis e seguros ao ser humano. Esse artigo visa analisar os fatores que levam ao crescimento da produção e investimento em cosméticos naturais (verdes), através do estudo dos processos e insumos utilizados na fabricação de cosméticos naturais, estabelecendo as vantagens da produção orgânica e sustentável, a qual tem apelo cada vez maior no mercado consumidor. Como metodologia foi utilizada a pesquisa bibliográfica, à partir do levantamento de referências teóricas já analisadas, e análise comparativa entre produtos já conhecidos no mercado.
\end{abstract}

Palavras-chave: Cosmético. Matéria Prima Natura. Sustentabilidade. Produção Sustentável.

ABSTRACT: Due to the increasing demand and the vanity of the consumers of the current market, it is not surprising the constant growth of the Brazilian cosmetic industry and the development of new products seeking to satisfy, more and more, the desire of consumers. With the increased use of natural cosmetics, a new niche market for cosmetics has emerged, called "green cosmetics", which are produced only by natural and organic

\footnotetext{
' Farmacêutica Bioquímica pelas Faculdades Adamantinenses Integradas, desde 2oro (atual UNIFAI) e Engenheira de Produção pelo UNIVEM, Centro Universitário Eurípedes Soares da Rocha, desde 2018, possui experiência em distribuição farmacêutica, laboratório de matérias primas farmacêuticas, fitoterápicos e varejo farmacêutico, além de ter atuado com elaboração de projetos de proteções de linhas de produção industrial, referentes a NRI2.

${ }^{2}$ Engenheira de Produção pelo UNIVEM, Centro Universitário Eurípides Soares da Rocha, Pós- Graduada em Gerenciamento de Projetos pela FGV, Fundação Getulio Vargas. Possui experiência em projetos de melhoria contínua nos segmentos de higiene e limpeza e colágeno bovino assim com pesquisa e desenvolvimento de embalagens metálicas, 3 peças, para indústria alimentícia.

3 Engenheira de Produção pelo UNIVEM, Centro Eurípedes Soares da Rocha, possui experiência em Mecânica de usinagem, desenvolvimento de produto e pesquisa, qualidade industrial e atendimento ao cliente, além de atuar em projetos de melhorias contínua e redução de custos.
} 
products. Subsequently, as a result, "green consumers", who are consumers of cosmetics that do not use synthetic substances and / or animal derivatives, have emerged because they are more sustainable and safe for humans. This article aims, precisely, at analyzing the factors that lead to this growth mentioned above, through the study of the processes and inputs used in the manufacture of natural cosmetics, establishing the advantages of organic and sustainable production, which has an increasing appeal in the market consumer.

Keywords: Cosmetic. Natural Raw Material. Sustainability. Sustainable Production.

\section{INTRODUÇÃO}

O setor de cosméticos demanda investimentos constantes e inovação contínua, no desenvolvimento de novos produtos, que tenham a capacidade de atender a uma grande e diversa gama de consumidores, visando o desenvolvimento sustentável e maior consciência em relação aos problemas ambientais. A competitividade do mercado aumenta juntamente com a motivação pelo desempenho por parte das empresas, levando-as a ajustar-se às leis ambientais, e também, buscando novos produtos e processos, obtidos através da tecnologia.

Como aponta Gonçalves (2016) atualmente, a capacidade de viver dentro dos recursos naturais disponíveis e a conscientização da sociedade, são fatores determinantes para nossa qualidade de vida. Baseado neste fato, é crescente, no setor de cosméticos, o número de empresas que visam a sustentabilidade, combinando as obrigações sociais e ambientais, ao seu retorno econômico.

O presente artigo visa identificar as vantagens e justificar o aumento da produção e investimento em cosméticos naturais (verdes), buscando um apelo ambiental cada vez mais sustentável e ecoeficiente, como uma maneira estratégica de adentrar competitivamente no setor de cosméticos industriais.

\section{METODOLOGIA}

Pesquisa bibliográfica através de materiais procurados em livros, artigos e internet de forma descritiva e pesquisas exploratórias, em busca de definir objetivos e estabelecer informações sobre o assunto de estudo. Segundo Fonseca (2002, p.32):

A pesquisa bibliográfica é feita a partir do levantamento de referências teóricas já analisadas, e publicadas por meios escritos e eletrônicos, como livros, artigos 
científicos, páginas de web sites. Qualquer trabalho científico inicia-se com uma pesquisa bibliográfica, que permite ao pesquisador conhecer o que já se estudou sobre o assunto. Existem, porém, pesquisas científicas que se baseiam unicamente na pesquisa bibliográfica, procurando referências teóricas publicadas com o objetivo de recolher informações ou conhecimentos prévios sobre o problema a respeito do qual se procura a resposta.

A pesquisa apresenta ainda, dados comparativos entre marcas conhecidas mundialmente, porém, não expostas devido à sigilo legal e ética profissional. A comparação se dá através da análise de compostos e valores de determinadas marcas disponíveis no mercado, mostrando as vantagens de um produto totalmente natural, de seu processo produtivo, e de seu valor perante a concorrência.

\section{REVISÃO TEÓRICA}

O Desenvolvimento Sustentável teve seu início de debate em 1972, através de uma Conferência Mundial sobre o Homem e o Meio Ambiente, conhecida como a Conferência de Estocolmo (PIMENTA \& NARDELLI, 2015).

O termo "sustentabilidade" vem se repetindo todos os dias através das mídias e feiras mundo à fora e empresas de diferentes setores, como a farmacêutica e cosmética. Estas buscam, cada vez mais, se dedicar à comercialização de produtos orgânicos e/ou naturais, certificados pelas empresas IBD e Ecocert, os quais seguem padrões rígidos de qualidade, até mesmo na escolha de matérias-primas e de suas substâncias orgânicas. $O$ resultado dessa rigorosidade é a fabricação de produtos mais receptivos para a pele, que causam menos alergias e irritabilidades.

No contexto empresarial, é conhecido que o meio ambiente é fonte de recursos produtivos, como matérias-primas, energia, entre outros, possibilitando, ainda, outputs desejados como resultados dos processos produtivos, tais como, bens e serviços desejados (BÁNKUTI, 20I4).

De acordo com a Companhia de Tecnologia de Saneamento Ambiental (CETESB) e a ABIHPEC, os principais impactos ambientais do segmento cosmético e de higiene pessoal, estão associados ao uso de água, tanto na incorporação das formulações dos produtos, quanto na limpeza e lavagem de máquinas e equipamentos. $\mathrm{O}$ uso de energia para aquecimento e resfriamento de itens durante os diversos processos também pode servir de impacto ambiental considerável, além do uso de matérias-primas e produtos 
auxiliares tóxicos, irritantes ou corrosivos, que geram principalmente solventes orgânicos, efluentes líquidos, resíduos de embalagens e outros tipos de resíduos sólidos, além de emissões de gases na atmosfera. Considerando todos estes fatores, a ABIHPEC aponta como tendências no segmento, aspectos relativos à sustentabilidade, biodiversidade, socioambiental e o apelo "vegetal" cada vez maior nos produtos, o que ratifica e deixa claro a importância de ações estratégicas ambientais nesse âmbito, além dos métodos de processos produtivos menos poluidores e agressivos ao meio ambiente, neste setor (BANKUTI, 2014).

Bankuti (2014) ainda explica que a utilização de recursos naturais menos impactantes em substituição aos insumos químicos está, definitivamente, incluída e definida na política de sustentabilidade das empresas atuais.

$\mathrm{Na}$ oitava reunião anual (ICCR-8) entre 8 e io de julho de 20I4, realizada em Otawa, no Canadá, a Cooperação Internacional sobre a Regulamentação dos Cosméticos (ICCR International Cooperation on Cosmetic Regulation), discutiu sobre dúvidas e perguntas frequentes sobre a conservação de produtos cosméticos, sendo estas disponibilizadas pelo site da ABIHPEC.

O referido documento diz que produtos cosméticos com elevado teor de água, como cremes e loções, possuem a necessidade de conter conservantes para manter a segurança de seu uso e as condições adequadas exigidas. Os produtos autoconservantes não necessitam de conservantes, salvo se a utilização pelo consumidor for suscetível de resultado de crescimento microbiano. Como exemplo, pode-se citar os batons e diversos outros produtos de maquiagem que são utilizados repetidamente. Estes podem estar suscetíveis de desenvolvimento de bolor superficial caso sua formulação for ausente de conservante antifúngico (Arquivo ABIHPEC, 2014).

Havendo ou não mensagens publicitárias, denominações comerciais específicas ou indicações de rotulagem, quaisquer produtos cosméticos devem ser conservados e testados, adequadamente, sendo de notória importância no que diz respeito aos produtos que possuam água em sua formulação, já que os microrganismos se desenvolvem na presença de umidade. Os cosméticos considerados "naturais" ou "orgânicos" não são diferentes, devendo ser expostos ao mesmo nível de testes de qualidade para garantir que são 
conservados de maneira adequada e que oferecem segurança ao consumidor, tal como qualquer outro cosmético (Arquivo ABIHPEC, 2014).

O SEBRAE (2017) ainda explica, que para que um cosmético seja considerado totalmente natural, devem ser seguidos rígidos padrões nos processos de formulação, além do fato de não haver a presença de componentes químicos entre seus componentes, impedindo a utilização de conservantes nos produtos. $O$ não uso desses conservantes encurtam o tempo de validade dos cosméticos, distanciando as grandes indústrias deste mercado, dando espaço para que empreendimentos voltados para o desenvolvimento de cooperativas sustentáveis ganhem força nesse ambiente de competição e negócio

\section{I Análise do processo produtivo de cosméticos naturais}

Segundo as ideias de negócios sustentáveis do SEBRAE (2012) em seu modelo de cadeia produtiva de cosméticos a base de mel apresentado no relatório de estudo de mercado de Cosméticos à base de produtos naturais, as partes do processo produtivo de um cosmético natural são:

- Recepção de matéria-prima, embalagens e outros materiais;

- Depósito de matérias-primas;

- Depósito de embalagens;

- Depósito de rotulagens;

- Setor de fabricação alimentado por água, energia e equipamentos;

- Área de envase;

- Rotulagem e embalagem;

- Depósito de produto acabado;

- Área de Expedição.

Em relação ao processo produtivo de cosméticos naturais, algumas exigências devem ser seguidas criteriosamente, como no caso dos testes de eficácia de tais cosméticos, os quais não devem ser realizados em animais, e ainda na forma de descarte dos efluentes e excedentes produtivos, que devem estar de acordo com a legislação ambiental Resolução CONAMA 357 de 2005, que dispõe sobre a classificação dos corpos de água e diretrizes 
ambientais para o seu enquadramento e estabelece condições e padrões de lançamento de efluentes. (RABELO, SEBRAE, 2012).

As embalagens dos cosméticos naturais considerados sustentáveis também devem ser avaliadas, analisando seu ciclo de vida, de maneira que não se tornem lixo urbano.

Conforme o Guia Técnico Ambiental da CETESB (2012), o relacionamento entre as indústrias de cosméticos naturais e seus fornecedores em geral, também deve assegurar a sustentabilidade de todo o negócio da empresa, assim como os diferentes setores industriais (GONÇALVES, 2016).

Sendo assim, o diferencial da mistura de componentes totalmente in natura, se dá através da não necessidade de altas temperaturas em seu processamento e mistura, evitando fumaças e consequente poluição ao meio ambiente, além de não causar alterações na função dos ativos naturais utilizados na formulação.

\section{I.I Vantagens deste processo produtivo}

Atualmente, os consumidores estão levando em consideração a prática da sustentabilidade nas indústrias, o que influencia muito na modificação e investimentos em processos produtivos que reduzam os efeitos negativos, tanto ao meio ambiente quanto à saúde do homem (CROSTON, 2014).

Segundo a ABIHPEC (2014), produtos com ingredientes e processos naturais estão ganhando espaço nas prateleiras e as vendas estão crescendo, mesmo o valor sendo mais elevado.

O SEBRAE (2017) ainda reforça que o segmento de cosmético natural vivencia pleno crescimento, tendendo a permanecer nesse patamar durante os próximos anos, já que se alinham às demandas da sociedade, que luta por um mundo mais economicamente justo $e$ altamente sustentável.

Neste sentido, a procura das pessoas por produtos naturais e sustentáveis faz com que este tipo de produto tenha muitas vantagens para a empresa que além de atender a esta demanda também ganha com um menor uso de energia elétrica na fabricação dos produtos, redução da taxa de poluição ao meio ambiente, redução de riscos ao trabalhador e consequente melhoria do meio em que o homem vive, em médio e longo prazo. 


\subsection{Insumos naturais}

Como aponta Santos (2007) os vegetais têm sido utilizados como fonte medicamentosa, nas formas de chás, infusões, macerados, tinturas e outras formulações preparadas à base de plantas. Alcalóides, flavonóides, cumarinas, isoflavonóides, taninos, são originários de diversas vias metabólicas, tendo importância nos mecanismos de defesa das plantas, contra predadores. As mesmas substâncias podem ter função antimicrobiana contra bactérias gram-positivas, gram-negativas, leveduras e fungos. As propriedades bactericidas, fungistáticas, bacteriostáticas e fungicidas oriundas dos vegetais, estão sendo comprovadas, cada vez mais, através de pesquisas, e comprovadas e avaliadas através de ensaios "in vitro", o que mostra a real eficiência dos vegetais em produtos cosméticos.

Segundo Rabello (2005, apud WEISS et al., 2017, p. 5) as matérias-primas para fabricação de cosméticos podem ser caracterizas como: pigmentos, princípios ativos, óleos essenciais, veículo, emolientes, conservantes, corretivos, corantes ou perfumes. Sendo estas segregadas como de origem orgânica ou sintética, sendo a primeira adquirida a partir de minerais; vegetais; e animais, enquanto a segunda de carbonato de cálcio, ácido salicílico e cânfora.

Em relação às matérias-primas que caracterizam os cosméticos isentos da presença de insumos industrializados estas podem ser orgânicas ou naturais. Os insumos caracterizados como naturais são oriundos de minerais; vegetais e animais, contudo os orgânicos segundo o Ministério da Agricultura, Pecuária e Abastecimento (2016) são os oriundos de um sistema orgânico de produção agropecuária através de um processo extrativista de forma sustentável, desta forma, estes necessitam ser certificados por organismos credenciados no Ministério da Agricultura, Pecuária e Abastecimento (MAPA).

$\mathrm{Na}$ cadeia de cosméticos ecológicos, as indústrias de extração e processamento, assim como com o apoio de cooperativas e associações de produtores rurais, aparecem como principais responsáveis na cadeia de valor, em decorrência do papel desempenhado pelas matérias-primas no desenvolvimento e sucesso do segmento (SEBRAE, 2012). Desta forma, é necessário ressaltar o aumento da competitividade brasileira em relações aos 
mercados externos em decorrência da sua vasta biodiversidade em insumos naturais ou orgânicos, como vegetais, extratos e óleos essenciais.

Um insumo natural que demonstra vantagens em seu uso industrial é a argila verde, que deve ter coloração esverdeada e sem granulações. Sua coloração deve-se à presença de óxido de ferro, que atua em sinergia com outros minerais presentes (RIBEIRO, 20Io). Possui maior diversidade em elementos. Rica em silício, desinfiltra o interstício celular, é esfoliante suave, promove a desintoxicação e regula a produção sebácea (NEUSA, 2006). É indicada para peles oleosas e acnéicas, tendo ação adstringente, tonificante, estimulante, combate edemas, secativa, bactericida, analgésica e cicatrizante (BUSKO, 2010).

\subsection{Custo benefício insumos naturais $\mathrm{x}$ convencionais}

Atualmente, os consumidores ecológicos, ou comumente conhecidos como consumidores "verdes", são preocupados com o meio ambiente e com os componentes de seus produtos, desde o plantio até mesmo com a forma com que o produto é embalado, levando em consideração fatores de geração e manejo de resíduos em vias de considerar o impacto ambiental causado. Desta forma, estes se encontram dispostos a dispender uma parcela considerável por produtos mais naturais e embalagens biodegradáveis, assim como com matérias-primas livres de fragrâncias, corantes e aromatizantes sintéticos (WEISS et al., 2017, p. 3).

Para identificação do comparativo de custo benefício serão analisados os preços e componentes de dois produtos, tendo como base o mesmo local para verificação e comparação. Considerando a proteção das marcas examinadas elas serão caracterizadas por nomes fictícios, a Empresa $\mathrm{X}$ o produto é uma Máscara Facial de Argila Pura de 40g, enquanto a Empresa Y, uma Máscara Facial de Argila de 8og. Ambas foram encontradas através do website americanas.com na última semana do mês de junho de 2018.

A Máscara Facial de Argila da Empresa Y possui em sua composição: copaiba officinalis oil, hamammelis virginiana extract, matricaria chamomilla extract, argilla, hectorite, tea tree water leaf, própolis extract, bisabolol, aloe barbadensis extract, tocopheryl acetate, eugenia caryophyllata essential oil, lavandula officinalis essential oil, xanthan gum, chondrus crispus 
(carrageenan), sodium citrate, eugenol, linalool. Esta possui certificado IBD de ingredientes naturais sendo $85 \%$ de insumos orgânicos, isento de parabenos, corantes e fragrâncias artificiais, formaldeídos, silicones, derivados de petroquímicos, ingredientes transgênicos e irradiados não sendo testado em animais e por 8 og no site mencionado pode ser encontrado por $\mathrm{R} \$ 32,90$.

Em contrapartida na Máscara Facial Argila Pura da Empresa X seus ingredientes são: aqua, water, kaolin, montmorilllonite, lecithin, polysorbate 20, butylene glycol, propylene glycol, oryza sativa starch, cl 77499, iron oxides, moroccan lava clay, charcoal poder, caprylyl glycol, citric acid, xanthan gum, polyglycerin-Io, polyglyceryl-ı, myristate, polyglyceryl stearate, sodium dehydroacetate, phenoxyethanol, lonalool, limonene, parfum/fragrance dispostos em $40 \mathrm{~g}$ de produto, encontrado no site por $\mathrm{R} \$ 30,90$.

Analisando os fabricantes das máscaras, segundo Bortolozi via Valor Econômico (2016) a Empresa $\mathrm{X}$ é uma das líderes nacionais no segmento de cosméticos fundada em meados de r9io tendo um lucro líquido de aproximadamente 3 bilhões de euros em 2016 (BORTOLOZI, 2017), enquanto a Empresa Y fundada em 2008, está há io anos no mercado e foi a pioneira em comercialização de cosméticos com insumos orgânicos rastreados no Brasil.

A Máscara Facial de Argila Pura não possui todos os ingredientes naturais, contendo em sua formulação compostos químicos, enquanto a Máscara Facial de Argila é caracterizada com $85 \%$ de insumos orgânicos rastreados, quanto ao peso a primeira apresenta $40 \mathrm{~g}$ e a segunda o dobro da mesma, 8og, já em relação aos valores a máscara da Empresa X custa atualmente no mercado $\mathrm{R} \$ 30,90$ enquanto a da Empresa $\mathrm{Y}$ a $\mathrm{R} \$ 32,90$.

Desta forma, considerando-se que ambas apresentam benefícios à pele e atendem as expectativas do mercado, somente uma das duas possui apelo sustentável, assim como o peso de uma grama (Ig) da líder de negócio sai por $\mathrm{R} \$ 0,7725$ enquanto da pioneira orgânica R\$o,4II25, sendo perceptível que o investimento em insumos naturais no processo de fabricação se garantindo de fato a qualidade do produto e assegurando o resultado esperado pelo cliente, é financeiramente e esteticamente atrativo, sendo necessário investir continuamente em pesquisas e desenvolvimento para garantir o avanço do setor. 


\section{RESULTADOS}

A partir da revisão teórica pesquisada e analisada foi possível identificar que os processos de fabricação da indústria de cosméticos têm apresentado abertura e possibilidades promissoras de crescimento. $\mathrm{O}$ mercado anseia por produtos sustentáveis de caráter natural e orgânico, que apresentem etapas de fabricação que não agridam ao meio ambiente e promovam o aproveitamento dos recursos naturais abundantes no planeta de forma ordenada e respeitosa. Percebe-se que os "consumidores verdes" são caracterizados por um público-alvo exigente que pesquisa e procura saber as origens das matérias-primas dos produtos que possam vir a comprar, esta por si apresenta um desafio aos novos e mesmo aos antigos empresários dos segmentos de cosméticos e fármacos que necessitam se atualizar e investir em pesquisa e desenvolvimento para aprofundar os conhecimentos dos componentes naturais e suas propriedades, benefícios e parâmetros.

Outra circunstância que demonstra o cenário otimista dos processos envolvendo insumos naturais, no que tange a benefícios econômico-sociais permite a aproximação do empresário industrial com o produtor rural a partir do momento que necessita de um

maior contato e conhecimento da procedência do plantio e manejo agregando valor ao fornecedor na cadeia, quando este se sente de fato como peça importante e se vê parte do produto final.

As análises das máscaras faciais a base de argila com características e objetivos similares possibilita a confirmação de que um processo de fabricação a partir de insumos naturais permite à empresa ingressar no mercado a um preço competitivo com grandes marcas de produtos já estabelecidos, demonstrando o potencial do segmento de crescer exponencialmente com o passar dos anos e de forma sustentável não contendo em suas formulações químicos agressivos.

\section{CONSIDERAÇÕES FINAIS}

A partir do levantamento teórico e analisando as diferentes marcas no mercado com seus respectivos preços e público-alvo, conclui-se que se faz necessário investimentos em produtos e cosméticos com um maior apelo sustentável, menos agressivos aos consumidores e ao meio em que vivemos. 
Como forma de promover incentivos a este segmento e destacar as vantagens em relação às concorrentes enfatizam-se benefícios como: econômica em relação a utilização de instrumentos e maquinários de aquecimento para formulações por se tratar de um produto ausente de conservantes sintéticos, como no caso da máscara facial anti-acne a base de própolis e argila, preparada inteiramente em um processo à frio, assim como evitando a emissão de gases e fumaças prejudiciais ao ecossistema, rapidez no preparo das formulações e baixo risco ao trabalhador.

Assim como este artigo ressalta as vantagens e demais informações quanto as propriedades dos produtos naturais, ressaltando as particularidades dos insumos advindos em meio natural e que possuem diversos benefícios a saúde, incentivando desta forma aplicações financeiras de cunho educacional e inovador para ampliação da cadeia de conhecimento para aplicação em indústrias.

\section{REFERÊNCIAS}

ABIHPEC. Perguntas frequentes (FAQ) de caráter geral e técnico sobre conservantes em produtos cosméticos. International Cooperation on Cosmetics Regulation (ICCR). Grupo de Trabalho da ICCR sobre a conservação de produtos cosméticos. Disponível em: <https://www.abihpec.org.br/novo/wp-content/uploads/ICCR-CONSERVACAO-DEPRODS-COSMETICOS.pdf>, acesso em 25/o4/2018, às I9h48min.

ABIHPEC. Associação Brasileira da Indústria de Higiene Pessoal, Perfumaria e Cosméticos. Panorama do Setor Higiene Pessoal Perfumaria e Cosméticos. 2018.

Perguntas frequentes (FAQ) de caráter geral e técnico sobre conservantes em produtos cosméticos. International Cooperation on Cosmetics Regulation (ICCR). Grupo de Trabalho da ICCR sobre a conservação de produtos cosméticos. Disponível em: 〈https://www.abihpec.org.br/novo/wp-content/uploads/ICCR-CONSERVACAO-DEPRODS-COSMETICOS.pdf>, acesso em 25/o4/2018, às I9h48min. 
ABIHPEC- Associação Brasileira da Indústria de Higiene Pessoal, Perfumaria e Cosméticos. Panorama do Setor Higiene Pessoal Perfumaria e Cosméticos. V. 7-05-I4. São Paulo. 2014.

ABIHPEC- Associação Brasileira da Indústria de Higiene Pessoal, Perfumaria e Cosméticos. III Caderno de Tendências 2014- 2015: Higiene Pessoal- Perfumaria e Cosméticos. São Paulo. BB Editora. 20I4.

ANVISA. Disponível em:〈http://www.anvisa.gov.br/anvisalegis/resol/12_78_mel.htm〉, acesso em 24/o6/2018, às 14 ho3min.

BÁNKUTI, S. M. S; BÁNKUTI, F. I. Gestão ambiental e estratégia empresarial: um estudo em uma empresa de cosméticos no Brasil. Gest. Prod., São Carlos, v. 2I, n. I, p. I71I84, 2014. Disponível em: 〈http://www.scielo.br/pdf/gp/v2InI/ar2v2InI.pdf〉, acesso em 23/04/2018, às 21ho2min.

BARBIERI, P. Fabrina; VICENTE, B. S. Eliara; YOSHIMURA, Cíntia. Dermocosmético Anti-ácne à Base de Argila e Própolis. Trabalho de Conclusão de Curso apresentado nas Faculdades Adamantinenses Integradas. Dez. 2oro. Arquivo Biblioteca UniFai.

BORTOLOZI, T. Líderes em Cosméticos Avançam. Disponível em: 〈http://www.valor.com.br/empresas/460o813/lideres-em-cosmeticos-avancam>, acesso em 24/o6/2018 as 22h15min.

BORTOLOZI, T. Lucro da L'Oréal soma 3,1 bilhões de euros em 2016, queda de 5,8\%. Disponível em: http://www.valor.com.br/empresas/486426o/lucro-da-1\%3Foreal-soma-31bilhoes-de-euros-em-2016-queda-de-58, acesso em 24/o6/2018 as 22h24min. 
BUSKO, A. Os benefícios da argila para pele. Disponível em: 〈http://www.dicasdemulher.com.br/os-beneficios-da-argila-para-pele/〉, cesso em I9/03/2018, Ioh29min.

CEtesB. Guia Técnico Ambiental 2012. Disponível em: $\langle$ http://www.crq4.org.br/downloads/higiene.pdf〉, acesso em 25/o6/2018, às 13h32min.

CROSTON, Glenn. Consumo e sustentabilidade no setor de higiene pessoal perfumaria e cosméticos. III Caderno de Tendências 2014- 2015: Higiene Pessoal, Perfumaria e Cosméticos. São Paulo. BB Editora. 2014.

FONSECA, J. J. S. Metodologia da pesquisa científica. Fortaleza: UEC, 2002. Apostila.

GONÇALVES, J, S; HENKES, J, A. Produção de Cosméticos de Forma mais Sustentável. Florianópolis - SC, v.5, n.I. p. 473-488. Abr/set. 2016. Disponível em: <file://C:/Users/usuario/Downloads/3670-8445-I-SM.pdf〉, acesso em 23/04/2018, às 2oh35min.

MARCUCCI, M. C. et al. Propriedades biológicas e terapêuticas dos constituintes químicos da própolis. Química Nova, São Paulo, v. 19, n. 5, p. 529-536, 1996.

NEUSA. O poder da argila. Disponível em: <http://blog.momentodaarte.com.br/20o6/ 07/o4/argila/>. Acesso em 19/03/2018, às ıoh3ımin.

PIMENTA, M., F., F.; NARDELLI, A., M., B. Desenvolvimento sustentável: os avanços na discussão sobre os temas ambientais lançados pela conferência das Nações Unidas sobre o desenvolvimento sustentável, Rio+2o e os desafios para os próximos 20 anos. UFSC. PERSPECTIVA, Florianópolis, v. 33, n. 3, p. 1257 - 1277, set./dez. 2015.

RABELO, Dayane. (Serviço Brasileiro de Apoio às Micro e Pequenas Empresas - 
SEBRAE). Fábrica de Cosméticos Ecológicos. Ideias de Negócios Sustentáveis. 2012. Disponível

em:

<file://C:/Users/usuario/Downloads/F\%C3\%Aıbrica\%2ode\%20Cosm\%C3\%A9ticos\%20 Ecol\%C3\%B3gicos.pdf>, acesso em 25/o6/2018, às I2hı5min.

SANTOS, Ana, L. R. Avaliação do Sistema Conservante em Formulação com Extrato Hidroalcóolico de Schinus terebinthifolius - ANACARDIACEAE. Natal - RN, 2007. Ministério da Educação e do Desporto. UFRN. Centro de Ciências e Saúde. Programa de

Pós-Graduação em Ciências Farmacêuticas. Disponível em: <file:///C:/Users/usuario/Downloads/Avalia\%C3\%A7\%C3\%A30\%2odo\%2osistema\%20c onservante\%20em\%2oformula\% $\mathrm{C}_{3} \% \mathrm{~A}_{7} \% \mathrm{C}_{3} \% \mathrm{~A}_{3}$ o.pdf $>$, acesso em 23/04/2018, às 2ohsimin.

SEBRAE, Nacional. Cosméticos Ecológicos Representam um Nicho para Pequenos Mercados. 2017. Set, Disponível em: <http://www.sebrae.com.br/sites/PortalSebrae/artigos/cosmeticos-ecologicosrepresentam-um-nicho-para-pequenosmercados,72985id70766e4IoVgnVCMiooooo3b74010aRCRD>, acesso em 26/o4/2018, às I8hı $8 \mathrm{~min}$.

SEBRAE, Nacional. Fábrica de Cosméticos Ecológicos. 2012. Disponível em: < http://www.sebraepr.com.br/Sebrae/Portal\%2oSebrae/Anexos/F\%C3\%Arbrica\%20de\%20 Cosm\%C3\%A9ticos\%2oEcol\% $\mathrm{C}_{3} \% \mathrm{~B}_{3}$ gicos.pdf , acesso em 24/o6/2018, às I4hismin.

SIMÕES, C. C. Estudo bioquímico da ação da própolis frente aos microorganismos presentes na saliva de humanos, 2007. 106 p. Dissertação (Mestrado em Odontologia). Faculdade de Odontologia, Universidade Federal da Bahia, Salvador. 2007. Disponível em: 〈https://repositorio.ufba.br/ri/bitstream/ri/ı1056/ı/Disserta\%C3\%A7\%C3\%A30_ODON TO_\%20Cinthia\%20Sim\% $\mathrm{C}_{3} \% \mathrm{~B} 5$ es.pdf $>$, acesso em 07/03/2018, às $14 \mathrm{~h} 42 \mathrm{~min}$. 
WEISS, C.; HAMAD, F.; FRANÇA, A. J. V. B. D. V. Produtos Cosméticos Orgânicos:

Definições

e Conceitos.

Disponível

em:

$\langle$ http://siaibibor.univali.br/pdf/Cristiani\%2oWeiss,\%20Felistin\%2oHamad.pdf $\rangle, \quad$ acesso em 24/o6/2018 as 12 h24min. 